\section{Being Closer to Normal}

I

feel something like a lizard emerging from hibernation under a rock. After a year of being a near recluse (with Zoom), I can now venture out, do more things, and even see my vaccinated friends and family_inside and without a mask! But oddly, it feels uncomfortable, and I remain tentative about what I do. I guess once you sink into a routine, it is hard to break out.

Of course, the clinic and the hospital provide guidance and policies that we must follow. Masks appear to be here to stay for quite a while, and travel restrictions remain in effect, which is fine, because all the big professional meetings we enjoy each spring and summer are being held virtually for the second year in a row.

I do have mask fatigue, though. I don't find wearing it onerous; I know the importance of this practice and am comfortable with a mask on. I have even learned to manage the fog on my eyeglasses! But good communication is hard with masks on. We all lip read to some extent, and many of our elderly patients with hearing impairment depend on it. In this regard, being able to see patients by telehealth has been a game changer. They can hear me, I can hear them, and hopefully, by the end of the visit, everything is clear.

I was hesitant about telehealth at first, knowing I would miss the powerful experience of in-person bonding with each new patient. And I do miss that, a lot. At this point, though, clear communication takes priority. So, until masks are no longer needed, I am sticking with this routine.

Of course, patients have adjusted to this routine as well. I find that patients don't mind driving into the clinic or hospital for a necessary imaging study or an infusion, but just to talk? Over and over, they have said they feel so comfortable being able to stay home and have the conversation there. Thus, even when we ditch the masks, I think for at least some established patients, this will remain the norm.

When COVID-19 shut down San Francisco last April, I believed the shutdown would last a few weeks or even a few months. I never thought more than half a million Americans would lose their lives due to this tiny virus. This has been a tragedy I still haven't completely processed. I certainly never imagined I would be still writing about COVID-19 in April 2021.

Thanks to science and commitment, we have vaccines available to protect us, and normalcy, or something like it, is within sight. So, like the little lizard, we can step out into the sun, take a deep breath, warm up, and get back to business.

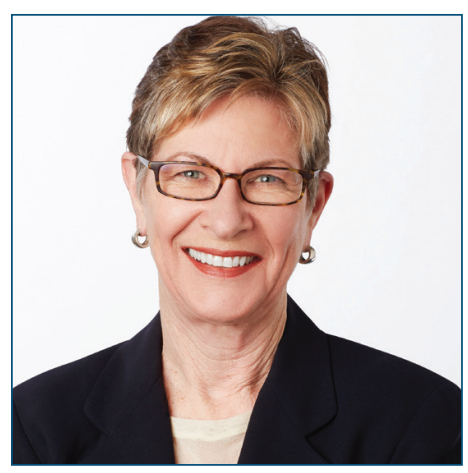

MARGARET TEMPERO, MD

Margaret Tempero, MD, is a Professor of Medicine and Director of the UCSF Pancreas Center and editor-in-chief of JNCCN. Her research career has focused on pancreatic ductal adenocarcinoma, especially in the area of investigational therapeutics. Dr. Tempero has served on the ASCO Board of Directors and as ASCO President. She currently serves on the ASCO Conquer Cancer Foundation Board. She codirected the AACR/ASCO Methods in Clinical Cancer Research and taught this course and similar courses in Europe and Australia. She was founding Chair of the $\mathrm{NCl}$ Clinical Oncology Study Section and served as a member and Chair of the $\mathrm{NCl}$ Board of Scientific Counselors Subcommittee A. She is a member of the Scientific Steering Committee and Chair of the Clinical and Translational Study Section for the Cancer Prevention \& Research Institute of Texas. She is or has been on the Scientific Advisory Boards of the Lustgarten Foundation, the Pancreatic Cancer Action Network, the V Foundation, The Alberta Canada Cancer Board, and the EORTC. She served as a member of the Oncology Drug Advisory Committee for the FDA. She has served as Deputy Director and Interim Director for the UNMC Eppley Cancer Center. She is Chief Emeritus of the Division of Medical Oncology at UCSF. She served as the founding Deputy Director and was later Director of Research Programs at the UCSF Helen Diller Family Comprehensive Cancer Center.

doi: 10.6004/jnccn.2021.0019

The ideas and viewpoints expressed in this editorial are those of the author and do not necessarily represent any policy, position, or program of NCCN. 